\title{
A Nova Lei de Migração Brasileira e sua Regulamentação da Concessão de Vistos aos Migrantes
}

\author{
The New Brazilian Migration Act and its Regulation in the \\ Concession of Visas to Migrants
}

\author{
Aylle de Almeida Mendes ${ }^{1}$ \\ Deilton Ribeiro Brasil ${ }^{1}$ \\ ${ }^{1}$ Universidade de Itaúna, Almenara, MG, Brasil
}

\begin{abstract}
Resumo: O presente artigo dialoga com os avanços e os desafios no estabelecimento de um novo marco legal quanto ao fluxo migratório no Brasil. Este trabalho apresenta o tema sobre a regulamentação da concessão de vistos aos migrantes a partir da perspectiva da Lei n. 13.445/2017. Em seguida, aborda-se sobre a concessão de alguns tipos de vistos, que é o documento que dá a seu titular a expectativa de ingresso em território nacional, e a sua regulamentação pelo Decreto n. 9.199/2017 apontando algumas de suas incongruências, o que poderá gerar cerceamento de direitos dos migrantes. A pesquisa é de natureza teórico-bibliográfica e segue o método descritivo-indutivo.
\end{abstract}

Palavras-chave: Nova Lei de Migração. Concessão de Vistos. Fluxo Migratório.

\begin{abstract}
This article aims to discuss the advances and challenges in the establishment of a new legal framework regarding the migratory flow in Brazil. It presents the theme on the regulation of the granting of visas to migrants from the perspective of n. 13.445/2017 Act. Then, it is approached about the granting of some types of visas, which is the document that gives its holder the expectation of entering the national territory, and its regulation by Decree n. 9.199/2017, pointing out some of its mismatches, which may to curtail the rights of migrants. The research is of theoreticalbibliographic nature following the descriptiveinductive method
\end{abstract}

Keywords: New Migration Act. Issue of Visas. Migratory Flow.

Recebido em: 03/12/2019

Revisado em: 29/09/2019

Aprovado em: 16/03/2020 


\section{Introdução}

O presente artigo tem como objetivo analisar a Lei n. 13.445/17, que foi regulamentada pelo Decreto n. 9.199/17, que disciplina a migração no Brasil no que se refere à concessão de vistos para migrantes para adentrar em território brasileiro. Tem como tema-problema a proposta de investigar se as inovações trazidas pela lei e os vetos de alguns artigos relacionados aos vistos no momento de sua promulgação e regulamentação pelo Decreto n. 9.199/17 ainda assim é garantidora dos direitos dos migrantes.

Adentrar no estudo sobre a nova Lei de Migração e do seu regulamento é relevante porque a nova lei é considerada um avanço das políticas migratórias no Brasil, já que significou o abandono de um viés unicamente voltado para a defesa nacional e à proteção do trabalhador nacional que se estendia desde a época da ditadura militar em relação ao imigrante. Dessa forma, o legislador brasileiro alinhou a política migratória sob manto protetor dos Direitos Humanos e da Constituição Federal de 1988, que tem como princípios basilares a fraternidade e a solidariedade bem como o combate a xenofobia e a criminalização da migração.

O trabalho além da introdução e das considerações finais foi divido em três partes: na primeira, buscou-se abordar sobre a nova Lei n. $13.445 / 2017$ e os seus aspectos gerais em face ao antigo regramento; na segunda parte, teceram-se algumas considerações sobre os tipos de vistos previstos na legislação e no regulamento; na última parte, foram investigadas algumas incongruências da regulamentação migratória sobre determinados tipos de vistos.

Utilizou-se da pesquisa teórico-bibliográfica e documental, a partir do estudo de obras, artigos e diplomas legais sobre a temática, e, por meio do método descritivo-indutivo, buscou-se estabelecer as premissas conceituais e práticas aplicadas na construção de uma política migratória no Brasil. 


\section{O Arcabouço Jurídico da Nova Lei de Migração Brasileira}

A Lei n. 13.445, de 24 de maio de 2017, disciplinou a migração no Brasil e estabeleceu princípios e diretrizes para as políticas públicas para o imigrante. Também a nova Lei de Migração substituiu a Lei n. 818/49 (regula a aquisição, a perda e a reaquisição da nacionalidade e a perda dos direitos políticos) e a Lei n. 8.615/80 (Estatuto do Estrangeiro), que tratava o não nacional como uma ameaça aos brasileiros e à imigração como uma questão de segurança nacional. $\mathrm{O}$ artigo $2^{\circ}$ do antigo Estatuto do Estrangeiro previa que na aplicação da lei atenderia precipuamente à segurança nacional, à organização institucional, aos interesses políticos, socioeconômicos e culturais do Brasil e à defesa do trabalhador nacional. $\mathrm{O}$ artigo $3^{\circ}$ acrescentava que "[...] a concessão do visto, a sua prorrogação ou transformação ficarão sempre condicionadas aos interesses nacionais", dando uma conotação ainda mais discricionária para a concessão ou a prorrogação do visto.

Segundo Brito (2013, p. 91), as dificuldades do Welfare State e o mercado de trabalho cada vez mais competitivo estão entre as causas das políticas restritivas à entrada de imigrantes e do ambiente cada vez mais adverso para eles. Concomitantemente, tem sido notável o ressurgimento de movimentos nacionalistas, principalmente na Europa, como se o reforço da identidade nacional por meio de concepções étnicas de nacionalidade, alimentadas por ideologias raciais antigas na cultura europeia, pudesse compensar as adversidades postas pela nova realidade econômica e demográfica.

Nesse contexto, as imigrações internacionais assumiram uma dimensão inusitada, expressa não só na atitude repressiva do Estado em relação aos imigrantes, mas também no aumento da sua importância na cena política. Essa politização tem duas dimensões essenciais. Uma delas refere-se aos imigrantes temporários que circulam dentro do mercado internacional de trabalho. De fato, a maioria dos imigrantes internacionais é temporária, pois a perspectiva de integração na sociedade de destino é mínima devido não só à competitividade no mercado de trabalho, mas também à quase total impossibilidade de qualquer tipo de mobilidade social ascendente. A institucionalização de diferenças sociais e culturais, que 
resvalam para um preconceito social e étnico, tem reforçado as adversidades aos imigrantes incentivando a temporalidade (BRITO, 2013, p. 91).

Percebe-se com isso que o imigrante era tratado de maneira discriminatória, porque era visto com desconfiança, fazendo-se necessário se precaver diante da ameaça causada pelo estrangeiro à soberania nacional e às relações de trabalho em detrimento do brasileiro. Com a nova Lei de Migração, o imigrante passa a ser sujeito de direitos e obrigações, prioriza-se a defesa dos direitos humanos.

A nova Lei n. 13.445/2017 inicia-se com uma mudança significativa, não é mais o estatuto do estrangeiro e sim a Lei de Migração. Muda-se o vocábulo estrangeiro - utilizada na Lei n. 8.615/1980 - para migrante na nova lei. Essa mudança não é apenas uma questão de terminologia, como destaca Guerra (2017, p. 7):

No caso da nova legislação, o legislador preferiu adotar a figura do migrante e do visitante (artigo1), em conformidade com a política consagrada na atualidade em prol dos direitos humanos. De certo modo, o termo empregado na Lei n. 13.445/2017 faz com que o indivíduo, que não seja nacional do Estado, não se sinta estranho e preterido no local que se encontra, como se um forasteiro fosse.

A Lei de Migração estabelece algumas definições importantes. Imigrante é toda pessoa nacional de outro país ou apátrida que trabalha ou reside e se estabelece temporária ou definitivamente no Brasil. O imigrante se distingue do visitante porque esse é o não nacional que vem ao Brasil para estadas de curta duração, sem pretensão de se estabelecer temporária ou definitivamente no território nacional, e são eles: os turistas, os artistas e as pessoas de negócio. Na lei constam outras definições, como a de emigrante que é o brasileiro que estabelece temporária ou definitivamente no exterior; o residente fronteiriço que é a pessoa nacional de país limítrofe ou apátrida que conserva a sua residência habitual em município fronteiriço de país vizinho; e o apátrida: pessoa que não seja considerada como nacional por nenhum Estado, segundo a sua legislação, nos termos da Convenção sobre o Estatuto dos Apátridas, de 1954, promulgada pelo Decreto n. 4.246, de 22 de maio de 2002. 
Não obstante essas definições trazidas pelo artigo $1^{\circ}$ da lei, foi vetado o seu inciso I que definia o migrante como "[...] pessoa que se desloca de país ou região geográfica ao território de outro país ou região geográfica, incluindo o imigrante, o emigrante, o residente fronteiriço e o apátrida". Para as razões do veto, alega-se que:

O dispositivo estabelece conceito demasiadamente amplo de migrante, abrangendo inclusive o estrangeiro com residência em país fronteiriço, o que estende a todo e qualquer estrangeiro, qualquer que seja sua condição migratória, a igualdade com os nacionais, violando a Constituição em seu artigo $5^{\circ}$, que estabelece que aquela igualdade é limitada e tem como critério para sua efetividade a residência do estrangeiro no território nacional. (BRASIL, 2017a, art. $\left.1^{\circ}\right)$

O artigo $5^{\circ}$ da Constituição Federal de 1988 prescreve que todos são iguais perante a lei, sem distinção de qualquer natureza, garantindo-se aos brasileiros e aos estrangeiros residentes no País a inviolabilidade do direito à vida, à liberdade, à igualdade, à segurança e à propriedade (BRASIL, 1988). Esse artigo restringe a proteção de direitos a estrangeiros "residentes no Brasil", entretanto, a interpretação desse artigo pelo Supremo Tribunal Federal vem estendendo a proteção dos direitos aos estrangeiros também não residentes no Brasil (JARDIM, 2017, p. 40). E dessa forma se harmonizando com o próprio texto constitucional e com a Declaração dos Direitos Humanos, ratificada pelo Brasil.

O Poder Executivo, ao vetar a definição de migrante - e tendo em vista a justificativa que acompanha o veto - contraria a própria fundamentação da lei e a Constituição Federal, quanto ao tratamento igualitário, fraterno e digno que deve ser conferido ao imigrante, independentemente de sua condição no território nacional, conforme interpretação da jurisprudência.

Nesse contexto, o Brasil adotou na Constituição Federal de 1988 uma sociedade fraterna, ao estabelecer em seu preâmbulo: 
Nós, representantes do povo brasileiro, reunidos em Assembleia Nacional Constituinte, para instituir um Estado Democrático, destinado a assegurar o exercício dos direitos sociais e individuais, a liberdade, a segurança, o bem-estar, o desenvolvimento, a igualdade e a justiça como valores supremos de uma sociedade fraterna, pluralista e sem preconceitos, fundada na harmonia social e comprometida, na ordem interna e internacional, com a solução pacífica das controvérsias, promulgamos, sob a proteção de Deus, a seguinte Constituição da República Federativa do Brasil. (BRASIL, 1988)

Da mesma forma, o artigo $3^{\circ}$, inciso I da Constituição Federal de 1988, constituiu como um dos seus objetivos fundamentais “"...] promover o bem de todos, sem preconceitos de origem, raça, sexo, cor, idade e quaisquer outras formas de discriminação [...]", garantindo, como prevê o artigo $5^{\circ}$, a igualdade aos brasileiros e estrangeiros, sem distinção de qualquer natureza e a punição a qualquer discriminação atentatória aos direitos e liberdades fundamentais.

Assim, Deilton Ribeiro Brasil (2018, p. 760) entende que,

O texto do preâmbulo revela que o Estado Democrático brasileiro instituído está destinado a assegurar o exercício dos direitos sociais e individuais e, considerá-los, como valores supremos de uma sociedade fraterna, pluralista e sem preconceitos, assim como a liberdade, a segurança, o bem-estar, o desenvolvimento, a igualdade e a justiça, devendo ser fundada na harmonia social e comprometida com a solução pacífica das controvérsias, tanto na ordem interna como, também, na ordem internacional.

A solidariedade, assim como a fraternidade, traz em seu âmago a preocupação para com o outro, ou seja, a solidariedade que impõe que uma pessoa se preocupe com o outro e que cada um se preocupe com o todo, assim como a fraternidade, que traz a ideia de preocupação com o irmão, a união, exige uma responsabilidade do indivíduo para com a sociedade.

A partir de tais previsões, percebidas aqui sob a ótica da perspectiva democrática de consideração dos direitos fundamentais,o concei- 
to de discriminação deve ser desatrelado da concepção de que esta seria um ato direto, isolado, praticado por determinada pessoa em momento igualmente determinado, passível de penalização específica e positivada na legislação. Segundo essa perspectiva, os atos discriminatórios devem ser percebidos além da ofensa direta à isonomia formal perpetrada na Constituição Federal de 1988, centrada na noção de justiça simétrica (MOREIRA, 2017).

O novo regramento, entretanto, traz novos princípios e diretrizes que devem reger a política migratória, em consonância com a Constituição Federal de 1988 e com tratados internacionais de que o Brasil é signatário, como: universalidade, indivisibilidade e interdependência dos direitos humanos; repúdio e prevenção à xenofobia, ao racismo e a quaisquer formas de discriminação; não criminalização da migração; não discriminação em razão dos critérios ou dos procedimentos pelos quais a pessoa foi admitida em território nacional; promoção de entrada regular e de regularização documental; acolhida humanitária; desenvolvimento econômico, turístico, social, cultural, esportivo, científico e tecnológico do Brasil; observância do disposto em tratados; e etc.

A política migratória brasileira também se aproxima das convenções e tratados já celebrados pelo Brasil, como a Declaração de Direitos Humanos. A Lei de Migração também se alinha aos princípios estabelecidos pela Constituição Federal de 1988, como o da dignidade da pessoa humana e da igualdade de tratamento, independentemente de raça, sexo, cor ou idade ou quaisquer outros tipos de discriminação.

Conforme elucida Paulo Henrique Gonçalves Portela (2017, p. 313):

[...] em decorrência da noção da universalidade dos direitos humanos, que estabelece que todos os indivíduos são igualmente destinatários dos mesmos direitos, sem distinção de qualquer espécie, e como consequência do incremento dos fluxos internacionais, inclusive de pessoas, e da formação de espaços internacionais comuns, como os blocos regionais, a situação jurídica dos não nacionais assemelha-se cada vez mais à dos nacionais, gozando aqueles de 
quase todos os direitos destes, sem o que o desenvolvimento das relações internacionais poderia encontrar obstáculos adicionais.

$\mathrm{O}$ artigo $4^{\mathrm{o}}$ da Lei n. 13.445/2017 prevê direitos aos migrantes no território brasileiro, como a inviolabilidade do direito à vida, à igualdade, à segurança e à propriedade. Também são assegurados direito à reunião familiar do migrante com seu cônjuge ou companheiro, filhos, familiares e dependentes; direito de transferir recursos decorrentes de sua renda e economias pessoais a outro país, observada a legislação aplicável; direito de reunião para fins pacíficos; direito à associação, inclusive sindical, para fins lícitos; acesso a serviços públicos de saúde e de assistência social e à previdência social, nos termos da lei, sem discriminação em razão da nacionalidade e da condição migratória; direito à educação pública, vedada a discriminação em razão da nacionalidade e da condição migratória.

O artigo 13, inc. II, da Declaração Universal dos Direitos Humanos estabelece que: "Todo o homem tem o direito de deixar qualquer país, inclusive o próprio, e a este regressar" (ONU, 1948). O que implicaria, em tese, que estaria consagrado o direito de ir e vir em escala mundial, permitindo uma livre circulação de pessoas entre os diversos Estados. Entretanto, nenhum Estado é obrigado a receber um imigrante em seu território, porque não existe nenhuma norma internacional que o obrigue a isso. Os Estados têm a discricionariedade de decidir quem vai entrar em seus respectivos territórios (PORTELA, 2017, p. 314).

Assim, cada Estado pode disciplinar de maneira diversa os requisitos de ingresso, permanência e retirada do território nacional. Em tempo de paz, no Brasil, desde que satisfeitas as condições previstas na Lei n. $13.445 / 2017$, qualquer pessoa pode entrar e permanecer no território nacional ou dele sair (MAZZUOLI, 2019, p. 647)

Por outro lado, tem-se a defesa dos direitos humanos em escala internacional. Fábio Konder Comparato (2015) ressalta a defesa da dignidade da pessoa humana, constante na Declaração dos Direitos Humanos:

O princípio da igualdade essencial do ser humano, não obstante múltiplas diferenças de ordem biológica e cultural que os dis- 
tinguem entre si, é afirmado no artigo II. A isonomia ou igualdade perante a lei, proclamada no artigo VII, é mera decorrência desse princípio. O pecado capital contra a dignidade humana consiste, justamente, em considerar e tratar o outro - o indivíduo, uma classe social, um povo - como um ser inferior, sob pretexto da diferença de etnia, gênero, costumes ou fortuna patrimonial. (COMPARATO, 2015, p. 241)

Como um valor fundamental, que é também um princípio constitucional, a dignidade humana funciona tanto como justificação moral quanto como fundamento jurídico-normativo dos direitos fundamentais. Sendo assim, ela vai necessariamente informar a interpretação de tais direitos constitucionais ajudando a definir o seu sentido nos casos concretos. Além disso, nos casos envolvendo lacunas no ordenamento jurídico, ambiguidades no direito, colisões entre direitos fundamentais e tensões entre direitos e metas coletivas, a dignidade humana pode ser uma bússola na busca da melhor solução. Mais ainda, qualquer lei que viole a dignidade, seja em abstrato ou em concreto, será nula (BARROSO, 2016, p. 64-66).

Em outras palavras, o princípio da dignidade humana é a qualidade intrínseca e distintiva reconhecida em cada ser humano que o faz merecedor do mesmo respeito e consideração por parte do Estado e da comunidade, implicando, nesse sentido, um complexo de direitos e deveres fundamentais que assegurem à pessoa tanto contra todo e qualquer ato de cunho degradante e desumano, como venham a lhe garantir as condições existenciais mínimas para uma vida saudável, além de propiciar e promover sua participação ativa e corresponsável nos destinos da própria existência da vida em comunhão com os demais seres humanos (SARLET, 2008, p. 63).

A autonomia é o elemento ético da dignidade humana. É o fundamento do livre arbítrio dos indivíduos, que lhes permite buscar, da sua própria maneira, o ideal de viver bem e de ter uma vida boa. A noção central aqui é a de autodeterminação: uma pessoa autônoma define as regras que vão reger a sua vida. A autonomia pressupõe o preenchimento de determinadas condições, como a razão (a capacidade mental de tomar decisões informadas), a independência (a ausência de coerção, de manipu- 
lação e de privações essenciais) e a escolha (a existência real de alternativas). A autonomia, portanto, corresponde à capacidade de alguém tomar decisões e de fazer escolhas pessoais ao longo da vida, baseadas na sua própria concepção de bem, sem influências externas indevidas. Quanto às suas implicações jurídicas, a autonomia está subjacente a um conjunto de direitos fundamentais associados com o constitucionalismo democrático, incluindo as liberdades básicas (autonomia privada) e o direito à participação política (autonomia pública). Por fim, ínsito à ideia de dignidade humana está o conceito de mínimo existencial, também chamado de mínimo social, ou o direito básico às provisões necessárias para que se viva dignamente (BARROSO, 2016, p. 81-85).

Dessa forma, os princípios fundamentais são concretizações ou exteriorização do princípio da dignidade humana, pois onde não houver respeito pela vida e pela integridade física e moral do ser humano, onde as condições mínimas para uma existência digna não forem asseguradas, onde não houver limitação do poder, enfim, onde a liberdade e a autonomia, a igualdade (em direitos e dignidade) e os direitos fundamentais não forem reconhecidos e minimamente assegurados, não haverá espaço para a dignidade humana e essa (a pessoa), por sua vez, poderá não passar de mero objeto de arbítrio e de injustiças (SARLET, 2008, p. 59).

O imigrante, tendo em vista a universalização dos direitos humanos, deverá ser tratado com dignidade. O Estado tem o controle de suas fronteiras e a discricionariedade em regular a entrada ou não do imigrante. Entretanto, ao fazê-lo terá que se nortear pelos tratados internacionais aos quais estão obrigados e aos princípios constantes em sua própria Constituição Federal.

\section{Alguns Comentários sobre os Tipos de Vistos Enumerados na Lei de Migração e no Decreto Regulamentador}

Várias são as situações que se apresentam que podem o migrante não ser documentado no país em que se encontra e, por isso, não ter seus direitos respeitados. Ele pode entrar clandestinamente, sem se apresentar a nenhuma autoridade de controle do país. Pode entrar portando 
documentos que se fizeram necessários para a sua entrada e depois permanecer por tempo superior ao permitido no documento ou, ainda, pode descumprir algum dever imposto pelo visto que autorizou o seu ingresso (WALDMAN, 2018, p. 43).

O capítulo II, da Lei de Migração, trata da situação documental do migrante e do visitante. São considerados documentos de viagem: o passaporte; o laissez-passer; a autorização de retorno; o salvo-conduto; a carteira de identidade de marítimo; a carteira de matrícula consular; o documento de identidade civil ou o documento estrangeiro equivalente, quando admitidos em tratado; o certificado de membro de tripulação de transporte aéreo; e outros que vierem a ser reconhecidos.

$\mathrm{O}$ visto é o documento que dá a seu titular a expectativa de ingresso em território nacional. $\mathrm{O}$ visto concedido pela autoridade diplomática ou consular confere ao seu titular mera expectativa de direito, mas em nenhuma hipótese garante esse ingresso (MAZUOLLI, 2019, p. 784). Por essa razão, a legislação elenca algumas hipóteses de impedimento de ingresso (artigo 45). Essas hipóteses incluem imigrantes expulsos, condenados por crimes graves, com documentação falsificada, sob alguma restrição sanitária etc. Em regra, o enquadramento em uma dessas hipóteses enseja a repatriação, a qual consiste em medida administrativa de devolução de pessoas em situação de impedimento ao país de procedência ou de nacionalidade (artigo 49). Em caso de repatriação, será feita imediata comunicação do ato fundamentado de repatriação à empresa transportadora e à autoridade consular do país de procedência ou de nacionalidade do migrante ou do visitante, ou a quem o representa (artigo 49, $\S 1^{\circ}$ ).

Para Daniel Chiaretti (2018, p. 308), é importante ressaltar que não será aplicada a medida de repatriação à pessoa em situação de refúgio ou de apatridia, de fato ou de direito, ao menor de 18 (dezoito) anos desacompanhado ou separado de sua família, exceto nos casos em que se demonstrar favorável para a garantia de seus direitos ou para a reintegração a sua família de origem, ou a quem necessite de acolhimento humanitário, nem, em qualquer caso, medida de devolução para país ou região que possa apresentar risco à vida, à integridade pessoal ou à liberdade da pessoa (artigo 49, § 4\%). Nessas hipóteses, é necessária a notificação da 
Defensoria Pública da União, já que a instituição tem atribuição para a tutela desses grupos vulneráveis (artigo 49, § $2^{\circ}$ ).

Os vistos serão expedidos pelas embaixadas, consulados-gerais, vice-consulados e por escritórios comerciais e de representação do Brasil no exterior, quando, nesse último caso, habilitados pelo órgão competente do Poder Executivo (artigo $6^{\circ}$ da Lei n. 13.445/17). E poderá não ser concedido: 1) quando não se preencher os requisitos para o tipo de visto pleiteado; 2) a quem comprovadamente ocultar condição impeditiva de concessão de visto ou de ingresso no país; 3) ou a menor de 18 anos desacompanhado ou sem autorização de viagem por escrito dos responsáveis legais ou de autoridade competente (artigo 10, da Lei n. 13.445/17).

Entretanto, muitos são os países que, por meio de tratado bilateral ou pelo exercício da reciprocidade, dispensam a aposição prévia do visto nos passaportes de cidadãos de nações amigas. O Brasil, por exemplo, não requer visto de entrada para os nacionais da maioria dos países da América Latina e da Europa Ocidental. Isso faz presumir que a presença dessas pessoas - ingresso de não nacional com passaporte não visado no país seja temporária, e não se poderia interpretar como abertura generalizada a imigração (REZEK, 2018, p. 235).

São cinco os tipos de vistos que poderão ser concedidos de acordo com o novo regramento legal: o de visita, o temporário, o diplomático, o oficial e o de cortesia. O visto de visita é concedido para os que venham ao Brasil sem a intenção de estabelecer residência, como ocorre nos casos de turismo, negócios, trânsito, atividades artísticas ou desportivas e outras hipóteses definidas em regulamento. Ao portador do visto de visita é vedado estabelecer atividade remunerada. Não obstante, poderá receber pagamento de governo, de empregador brasileiro ou de entidade privada a título de diária, ajuda de custo, cachê, pró-labore ou outras despesas com a viagem, bem como concorrer a prêmios, inclusive em dinheiro, em competições desportivas e em concursos artísticos ou culturais (artigo 13 da Lei n. 13.445/17).

Quanto ao prazo do visto de visita, o regulamento prescreve que poderá ser de até um ano, a não ser que haja determinação em contrário do Ministério das Relações Exteriores. Quando houver reciprocidade de 
tratamento pelos países, o prazo poderá ser de até dez anos, nos termos definidos por comunicação diplomática. O portador poderá entrar no país várias vezes até que o prazo de validade expire. No caso de visto emitido por meio eletrônico, o prazo também poderá ser superior a um ano a critério do Ministério das Relações Exteriores (artigo 15 do Decreto n. 9.199/17).

O prazo de estada é aquele durante o qual o seu portador poderá permanecer no território nacional e começa a contar a partir de sua entrada no país. O tempo de estada para os portadores do visto de visita é de até 90 dias, podendo ser prorrogado pelo Polícia Federal por até mais 90 dias, desde que não ultrapasse 180 dias a cada ano migratório, salvo as hipóteses em que o visto não poderá ser prorrogado, conforme aponta o $\S 7^{\circ}$ do artigo 29. Caberá a Polícia Federal, excepcionalmente, conceder prazo de estada inferior ao mencionado, ou reduzir, a qualquer tempo, o prazo previsto de estada do visitante (artigos 19 e 20 do Decreto n. 9.199/17). O visto de visita poderá ainda ser transformado em autorização de residência ou em visto diplomático, oficial ou de cortesia, desde que o visitante preencha os requisitos exigidos no decreto (artigo 30 do Decreto n. 9.199/17). Quanto aos vistos temporários, diplomáticos, oficiais e de cortesia, o seu prazo inicial será igual ao de sua validade (artigo 22 do Decreto n. 9.199/17).

$\mathrm{O}$ visto temporário é destinado àqueles que tenham a intenção de estabelecer residência no Brasil por prazo determinado. São os vistos requeridos com a finalidade de: pesquisa, ensino ou extensão acadêmica; tratamento de saúde; acolhida humanitária; estudo; trabalho; férias/trabalho; prática de atividade religiosa ou serviço voluntário; realização de investimento ou de atividade com relevância econômica, social, científica, tecnológica ou cultural; reunião familiar; atividades artísticas ou desportivas com contrato por prazo determinado. No visto temporário também se inclui o imigrante que seja beneficiário de tratado em matéria de vistos e também para outras hipóteses definidas em regulamento (artigo 14, da Lei n. 13.445/17).

$\mathrm{O}$ visto temporário para tratamento de saúde, de acordo com o regulamento, 
[...] estará condicionada à comprovação de meios de subsistência suficientes para custear o seu tratamento e a sua manutenção durante o período em que o tratamento for realizado, por recurso próprio, seguro de saúde válido no território nacional ou certificado de prestação de serviço de saúde previsto em tratado de que o País seja parte. (BRASIL, 2017a, art. 35 e parágrafos)

Esse artigo elucidou o fato de que a comprovação de meios de subsistência suficientes para o imigrante e ao seu acompanhante inclui também meios para o tratamento de saúde.

O visto temporário para acolhida humanitária destaca-se como inovação da Lei de Migração e poderá ser concedido ao apátrida ou nacional de qualquer país em situação de grave ou iminente instabilidade institucional, de conflito armado, de calamidade de grande proporção, de desastre ambiental ou de grave violação de direitos humanos ou de direito internacional humanitário, ou em outras hipóteses, na forma do regulamento. Como observa Luís Renato Vedovato (2018, p. 738), será permitida a ampliação desse visto para outras hipóteses, vez que a Lei de Migração não traz rol taxativo nesse caso.

Ainda de acordo com o Decreto n. 9.199/17, a definição dos detalhes da acolhida humanitária, como condições, prazos e requisitos, dependerá de um ato conjunto dos ministros de Estado da Justiça e Segurança Pública, das Relações Exteriores e do Trabalho (artigo 36, § $1^{\circ}$ ). Apenas com essa regulamentação é que será possível avaliar o instituto na prática. Importante ressaltar que a regulamentação não poderá contrariar a Lei de Migração, restringindo o instituto da acolhida humanitária a ponto de ocorrer um esvaziamento do instituto (CHIARETTI, 2018, p. 308).

$\mathrm{O}$ visto temporário para estudo, conforme regulamento, autoriza o estudante a frequentar curso regular ou realizar estágio ou intercâmbio de estudo e pesquisa vinculada à instituição de ensino definida, podendo a atividade ser remunerada desde que compatível com a carga horária do estudo (artigo 37 do Decreto n. 9.199/17).

Merece destaque alguns pontos relativos à Lei de Migração e mais especificamente à questão da documentação do migrante. Primeiro, que 
vários foram os vetos à lei pela Presidência da República, por intermédio da Casa Civil. Com relação ao visto temporário, há que se mencionar o veto ao parágrafo 10 do artigo 14 da lei que prescrevia que "[...] regulamento disporá sobre as demais hipóteses de concessão de visto temporário e sobre as especificidades de suas categorias, definindo condições, prazos e requisitos". Esse inciso abria possibilidade para que outras hipóteses de visto temporário pudessem existir, além daquelas definidas na lei. O argumento para esse veto foi o de que não seria recomendável permitir a existências de novas possibilidades criadas por regulamento, tendo em vista o risco de discricionariedade indevida e com potencial de gerar insegurança jurídica. $\mathrm{O}$ que denota uma preocupação com a segurança nacional, igual a presente no revogado Estatuto do Estrangeiro.

$\mathrm{O}$ visto temporário para fins de reunião familiar, conforme prevê o artigo 45 do regulamento, será concedido ao imigrante: cônjuge ou companheiro, sem discriminação alguma, nos termos do ordenamento jurídico brasileiro; filho de brasileiro ou de imigrante beneficiário de autorização de residência; que tenha filho brasileiro; que tenha imigrante beneficiário de autorização de residência; ascendente ou descendente até o segundo grau de brasileiro ou de imigrante beneficiário de autorização de residência; irmão de brasileiro ou de imigrante beneficiário de autorização de residência; ou que tenha brasileiro sob a sua tutela, curatela ou guarda. $\mathrm{O}$ visto de reunião familiar não poderá ser concedido quando o chamante (pessoa que já esteja no Brasil) for beneficiário de visto ou autorização de residência por reunião familiar ou de autorização provisória de residência. A lei visa a estimular a reunião familiar, ou seja, pessoa que já está no Brasil e quer trazer os seus familiares.

Os vistos diplomáticos e oficiais poderão ser concedidos a autoridades e funcionários estrangeiros que viajem ao Brasil em missão de caráter transitório ou permanente, representando Estado estrangeiro ou organismo internacional reconhecido. Ressalvado o disposto em tratado que contenha cláusula específica sobre o assunto, o titular do visto diplomático ou oficial somente poderá ser remunerado por Estado estrangeiro ou organismo internacional e não estará sujeito à legislação trabalhista brasileira (artigos 16 e 17 da Lei n. 13.445/17). Entretanto, o dependente de titular de visto diplomático ou oficial poderá exercer atividade remunerada no 
Brasil, sob o amparo da legislação trabalhista brasileira, desde que contenha cláusula sobre o assunto (artigo 17, da Lei n. 13.445/17).

$\mathrm{O}$ visto de cortesia, que não havia sido disciplinado especificamente pela lei, foi abordado pelo artigo 57 do regulamento, que prescreve que ele poderá ser concedido: às personalidades e às autoridades estrangeiras em viagem não oficial ao País; aos companheiros, aos dependentes e aos familiares em linha direta que não sejam beneficiários de visto diplomático; aos empregados particulares de beneficiários de visto diplomático, oficial ou de cortesia; aos trabalhadores domésticos de missão estrangeira sediada no país; aos artistas e aos desportistas estrangeiros que venham ao país para evento gratuito, de caráter eminentemente cultural, sem percepção de honorários no território brasileiro, sob requisição formal de missão diplomática estrangeira ou de organização internacional de que o Brasil seja parte; e excepcionalmente, a critério do Ministério das Relações Exteriores, a outras pessoas não previstas nas hipóteses elencadas. No entanto, o titular de visto diplomático, oficial ou de cortesia, fica responsável pela saída de seu empregado do território nacional, segundo o artigo 18 da Lei de Migração.

A autorização de residência, constante no artigo 30 da Lei de Migração, substituiu o antigo visto permanente disciplinado pelo antigo Estatuto do Estrangeiro. Segundo a Lei de Migração, a residência no Brasil poderá ser autorizada, mediante registro, ao imigrante, ao residente fronteiriço ou ao visitante que se enquadre nas hipóteses previstas na lei (MAZZUOLI, 2019, p. 650).

A lei inicialmente ampliava a autorização de residência para fins de reunião familiar que poderia ser estendida, por meio de ato fundamentado, a outras hipóteses de parentesco, dependência afetiva e fatores de sociabilidade. Havia a possibilidade de ampliação do vínculo familiar para vínculos sociais que, entretanto, foi vetado com a alegação de que isso poderia "[...] possibilitar a entrada de crianças sem visto, acompanhada de representantes por fatores de sociabilidade ou responsável legal residente e, com isso, facilitar ou permitir situações propícias ao sequestro de menores". 
Foi objeto de veto também pelo executivo o parágrafo único do artigo $6^{\circ}$ da Lei de Migração, que dispunha o seguinte:

[...] o visto poderá ser aposto qualquer documento de viagem emitido nos padrões estabelecidos pela Organização da Aviação Civil Internacional (OACI) ou pelo Comitê Internacional da Cruz Vermelha, não implicando sua oposição o reconhecimento de Estado, Governo ou Regime. (BRASIL, 2017a, art. $6^{\circ}$ )

As razões do veto foram no sentido de que não se dispunha de informações acerca do padrão do documento emitido pela Cruz Vermelha. Esse veto, inclusive, foi recomendado pelo Ministério da Justiça e Segurança Pública.

Uma das principais críticas aos vetos dos artigos da Lei de Migração foi em relação ao artigo 118 da lei, que previa anistia ao imigrante irregular que tivesse ingressado no país até 6 de julho de 2016 e que requeresse até um ano a autorização de residência. Alegou-se, como razões do veto, que se estaria concedendo anistia indiscriminada a todos os imigrantes, independentemente de sua situação migratória ou de sua condição pessoal, e que não se poderia também precisar qual a data de entrada do imigrante no território brasileiro. Entretanto, tal veto dificultou a regularização dos documentos e, assim, a integração dos migrantes que já se encontram no Brasil.

\section{Algumas Considerações Adicionais sobre o Decreto n. 9.199/17}

A nova Lei de Migração reservou à regulamentação alguns aspectos sobre a concessão de vistos, como: os requisitos para a concessão; o prazo de validade e a forma de contagem; o prazo máximo para a primeira entrada e para a estada do imigrante e do visitante no País; as hipóteses e as condições de dispensa recíproca ou unilateral do visto e das taxas e emolumentos consulares; e a solicitação e emissão de visto por meio eletrônico. O Decreto n. 9.199/17 dispõe sobre os vistos e o registro do migrante do artigo $4^{\circ}$ ao 94 . 
Há que se ressaltar alguns artigos do regulamento, no que se refere aos vistos, que foram duramente criticados e até mesmo entendidos como contrários ao espírito da Lei de Migração, vez que contraria a proteção dos direitos fundamentais, garantidos pela nova lei.

De acordo com o artigo 84, IV, da Constituição Federal de 1988, o Poder Executivo tem competência para expedir decretos e regulamentos para a sua fiel execução, sob pena de sobreposição de um poder sobre o outro. A Constituição Federal prevê mecanismos de correção e de adequação quando desobedecidos a norma constitucional e o equilíbrio entre os poderes.

A Lei de Migração estabelece ainda as situações da não concessão do visto (artigo 27 do Decreto n. 9.199/17) quais sejam: a quem não preencher dos requisitos para o tipo de visto pleiteado; a quem comprovadamente ocultar condição impeditiva de concessão de visto ou de ingresso no país; a menor de 18 anos desacompanhado ou sem autorização de viagem por escrito dos responsáveis legais ou de autoridade competente; a quem, no momento de solicitação do visto comportar-se de forma agressiva, insultuosa ou desrespeitosa para com os agentes do serviço consular brasileiro. Também a quem se enquadrar em pelo menos um dos casos de impedimento (artigo 11). Eventual negativa, contudo, não impede nova solicitação, desde que cumpridos os requisitos (artigo 27, parágrafo único, do Decreto n. 9.199/17) (CHIARETTI, 2018, p. 302-303).

Entre essas hipóteses em que não será concedido o visto, ainda de acordo com o artigo 27 do regulamento da Lei de Migração, o inciso IV estabelece que será negado o visto “[...] a quem, no momento de solicitação do visto, comportar-se de forma agressiva, insultuosa ou desrespeitosa para com os agentes do serviço consular brasileiro [...]", esse inciso é criticado por estabelecer um viés autoritário, contrariar a lei e pela possibilidade de gerar arbitrariedades (BRASIL, 2018, p. 770).

$\mathrm{O}$ artigo 28, inciso V, do Decreto n. 9.199/17 também dispõe que o visto não será concedido à pessoa "[...] que tenha praticado ato contrário aos princípios e aos objetivos dispostos na Constituição”. E, segundo ainda Deilton Ribeiro Brasil (2018, p. 768), ao não especificar o que seria isso, abre-se "[...] um campo discricionário para o Poder Executivo para recusar visto e autorização de residência de pessoas indesejadas". 
O visto temporário com a finalidade humanitária, que foi uma inovação da lei, não foi regulamentado pelo Decreto n. 9.199/17, que prescreve, no artigo 36, que "[...] ato conjunto dos Ministros de Estado da Justiça e Segurança Pública, das Relações Exteriores e do Trabalho definirá as condições, os prazos e os requisitos para a emissão do visto mencionado no caput para os nacionais ou os residentes de países ou regiões nele especificados". A inovação ora trazida pelo visto humanitário carece, então, de regulamentação a respeito.

Nesse sentido, Luís Renato Vedovato (2018, p. 739) pontua que:

[...] a nova regulamentação deveria se preocupar em estabelecer um rol exemplificativo de hipóteses de concessão de acolhida humanitária. Além disso, deveria estabelecer um rol exemplificativo de hipóteses de concessão da acolhida humanitária. Além disso, deveria estabelecer a competência da autoridade interna para decidir sobre se um caso específico é para acolhida humanitária. Facilitaria o processo, a existência de parâmetros para identificação de uma crise humanitária. Além disso, importante destacar que as hipóteses de acolhida humanitária não podem ser restritas às hipóteses de refúgio. Em outras palavras, se a acolhida humanitária repetir, como situações de concessão, os cenários já abarcados pelo refúgio, haveria negação desse direito e clara violação que está estabelecido no artigo 14, parágrafo $3^{\circ}$, da NLM.

Além dos vetos, que já haviam demonstrado uma postura contrária do executivo ao espírito da Lei de Migração, o Decreto n. 9.199, de 20 de novembro de 2017, que regulamentou a lei, permitiu a prisão do imigrante irregular, podendo se falar, nesse caso, que o regulamento é contra legem, vez que contraria princípio inserido pela Lei n. 13.445/17 de "não criminalização da migração", previsto no artigo $3^{\circ}$, inciso III.

Não obstante o descompasso da regulamentação da Lei de Migração, em alguns aspectos, não há como ignorar o fato de que a lei trouxe novas perspectivas no reconhecimento de direitos e obrigações dos migrantes. Alice Rocha da Silva (2016, p. 99) destaca antes do advento da lei que: 
a) existe uma forte tendência para o tratamento da questão migratória como um problema de segurança;

b) o tratamento humanitário e a regulamentação efetiva da situação do imigrante é a forma mais adequada de lidar com a complexa questão migratória internacional;

c) o Direito Administrativo global possui dinâmica própria e mecanismos adequados para a produção de soluções, mais ágeis para a crise migratória atual

Tem-se, por hora, o desafio de tornar efetiva a Lei de Migração, não obstante a sua regulamentação. O que apenas complementaria as disposições legais, se tornou um obstáculo para o tratamento igualitário entre os imigrantes no país.

A aplicação da nova Lei de Migração exige uma abordagem diferenciada do fenômeno migratório, com maior sensibilidade. Isso demanda, entre outras coisas, honestidade e rejeição aos diversos mitos que circundam as migrações. Estatísticas mostram que o Brasil recebe um fluxo migratório baixo. Há, ainda, muito desinformação sobre os próprios fluxos (CHIARETTI, 2018, p. 328).

\section{Conclusão}

A migração é inerente à vida do ser humano e faz parte de sua história. As migrações ocorrem por diversos fatores, como: quando se procura melhores condições de vida; para fugir de guerras e desastres ambientais; ou, simplesmente, por desejar se estabelecer em outra região, em razão do clima, da sociedade ou da família.

A Lei n. 13.445/17 buscou harmonizar-se aos direitos humanos, assegurados por meio de tratados dos quais o Brasil é signatário, e direitos fundamentais prescritos na Constituição Federal de 1988, como o direito à liberdade, à segurança e à inviolabilidade de domicílio. Em consonância com esses direitos, a lei estabelece que a política migratória brasileira será regida, entre outros princípios e diretrizes, pela universalidade; interdependência dos direitos humanos; pelo repúdio e prevenção à xenofobia, 
ao racismo e a quaisquer formas de discriminação; não criminalização da migração; e pela não discriminação em razão dos critérios e dos procedimentos pelos quais a pessoa foi admitida em território nacional.

Foram vetados, pelo Poder Executivo, 20 dispositivos da Lei n. $13.445 / 17$ para a sua aprovação. No que se refere aos vistos, foram vetados alguns dispositivos, como o $§ 10$ do artigo 14 da Lei de Migração, que impediu que o regulamento pudesse ampliar as hipóteses de visto temporário previstas na lei; e também houve o veto ao parágrafo único do artigo $6^{\circ}$ da Lei de Migração que permitia como documento de viagem os documentos emitidos pela Cruz Vermelha. Foi mencionado ainda o veto ao artigo 118, da lei de anistia, que apesar de não se relacionar diretamente com os vistos, põe em destaque a situação de muitos imigrantes que se encontram indocumentados no país e que foram impedidos de regularizar a questão documental em razão do veto a esse artigo.

No que se refere ao Decreto n. 9.199/17, quanto à regulamentação referente aos vistos, o que se apresenta mais evidente é, inclusive, a falta de regulamentação do visto temporário humanitário, o que pode acarretar cerceamento de direitos aos imigrantes que ingressam no país nessa situação.

Como resultado final, há que se pontuar que, naquilo em que o Decreto for considerado contrário às garantias asseguradas pela Lei de Migração, é necessário que haja uma organização da sociedade civil a fim de se tornar tais dispositivos inválidos por meio de um controle de legalidade, uma vez que o Decreto tem como objetivo primordial apenas a regulamentação da Lei de Migração sob pena de ocorrer uma eventual ofensa ao princípio da separação dos poderes.

\section{Referências}

BARROSO, Luís Roberto. A dignidade da pessoa humana no direito constitucional contemporâneo: a construção de um conceito jurídico à luz da jurisprudência mundial. 4. reimpressão. Belo Horizonte: Editora Fórum, 2016. 
BRASIL. Constituição Federal. Constituição da República Federativa do Brasil de 1988. Publicada no Diário Oficial da União, Brasília, 5 out. 1988. Disponível em: http://www.planalto.gov.br/ccivil_03/constituicao/ constituicaocompilado.htm. Acesso em: 26 nov. 2018.

BRASIL, Deilton Ribeiro. As dimensões políticas, sociais e econômicas da nova lei de migração brasileira e os direitos humanos em uma sociedade globalizada. Revista Argumentum, Marília-SP, v. 19, n. 3, p. 757-774, set.-dez. 2018. Disponível em: http://ojs.unimar.br/index.php/ revistaargumentum/article/view/573/322. Acesso em: 13 jan. 2019.

BRASIL. Lei n. 818, de 18 de setembro de 1949. Regula a aquisição, a perda e a reaquisição da nacionalidade, e a perda dos direitos políticos. Diário Oficial da União, Brasília, 29 de setembro de 1949. Disponível em: http:/www.planalto.gov.br/ccivil_03/LEIS/L0818.htm. Acesso em: 14 jan. 2019.

BRASIL. Lei n. 6.815, de 19 de agosto 1980. Define a situação jurídica do estrangeiro no Brasil, cria o Conselho Nacional de Imigração. Diário Oficial da União, Brasília, 21 de agosto de 1980. Disponível em: http:// www.planalto.gov.br/ccivil_03/leis/L6815.htm. Acesso em: 14 jan. 2019.

BRASIL. Lei n. 13.445, de 24 de maio de 2017. Institui a Lei de Migração. Diário Oficial da União, Brasília, 25 de maio de 2017a. Disponível em: http://www.planalto.gov.br/ccivil_03/_ato20152018/2017/lei/L13445.htm. Acesso em: 16 nov. 2018.

BRASIL. Decreto n. 9.199, de 20 de novembro de 2017. Regulamenta a Lei n. 13.445, de 24 de maio de 2017, que institui a Lei de Migração.

Diário Oficial da União, Brasília, 21 de novembro de 2017b.Disponível em: http:/www.planalto.gov.br/ccivil_03/_ato2015-2018/2017/decreto/ D9199.htm. Acesso em: 16 nov. 2018.

BRITO, Fausto. A politização das migrações internacionais: direitos humanos e soberania nacional. Revista Brasileira de Estudos de População, Rio de Janeiro, v. 30, n. 1, p. 77-97, jan.-jun. 2013. Disponível em: https:/www.rebep.org.br/revista/article/view/15/pdf_13. Acesso em: 13 jan. 2019. 
CHIARETTI, Daniel. Impactos da nova Lei de Migração na atividade jurisdicional. Revista da Escola da Magistratura do TRF da $4^{\text {a }}$ Região, Porto Alegre, RS, ano 5, n. 10, p. 289-331, 2018. Disponível em: https:// www.trf4.jus.br/trf4/controlador.php?acao=pagina_visualizar $\& \% 20$ id_pagina=1336. Acesso em: 13 jan. 2019.

COMPARATO, Fábio Konder. A afirmação histórica dos direitos humanos. 10. ed. São Paulo: Saraiva, 2015.

FERNANDES, Jean Marcel. A promoção da paz pelo direito internacional humanitário. Porto Alegre: Sergio Antônio Fabris Editor, 2006.

GUERRA, Sidney. A nova lei de migração no Brasil: avanços e melhorias no campo dos direitos humanos. [2017]. Disponível em: http:// www.e-publicacoes.uerj.br/index.php/rdc/article/view/28937/21967. Acesso em: 16 nov. 2018.

JARDIM, Tarciso Dal Maso. A lei migratória e a inovação de paradigmas. Cadernos de Debates Refúgio, Migrações e Cidadania, Brasília: Instituto Migrações e Direitos Humanos, v. 12, n. 12, 2017. Disponível em: https://www.acnur.org/portugues/wp-content/ uploads/2018/02/Caderno-de-Debates-12_Ref\%C3\%BAgioMigra\%C3\%A7\%C3\%B5es-e-Cidadania.pdf. Acesso em: 30 dez. 2018.

MACEDO, Paulo Emílio Vauthier Borges de. A ingerência humanitária e a guerra justa. [2018]. Disponível em: https://www.e-publicacoes.uerj. br/index.php/quaestioiuris/article/view/11617 Acesso em: 3 dez. 2018.

MAZZUOLI, Valério de Oliveira. Curso de direito internacional público. São Paulo: Editora Revista dos Tribunais, 2019.

MOREIRA. Adilson José. O que é discriminação? São Paulo: Editora Letramento, 2017.

OLIVEIRA, Antônio Tadeu Ribeiro. Migrações internacionais e políticas migratórias no Brasil. [2018]. Disponível em: http:// periodicos.unb.br/index.php/obmigra_periplos/article/view/16174/11521 Acesso em: 16 nov. 2018. 
ONU - ORGANIZAÇÃO DAS NAÇÕES UNIDAS. Declaração Universal dos Direitos Humanos de 1948. [1948]. Disponível em: http://www.unicef.org/brazil/pt/resources_10133.html. Acesso em: 19 dez. 2018.

PORTELA, Paulo Henrique Gonçalves. Direito internacional público e privado: incluindo noções de direitos humanos e direito comunitário. 9. ed. Salvador: JusPODIVM, 2017.

REZEK, José Francisco. Direito internacional público: curso elementar.17. ed. São Paulo: Saraiva, 2018.

SARLET, Ingo Wolfgang. Dignidade da pessoa humana e direitos fundamentais na Constituição Federal de 1988. 6. ed. Porto Alegre: Livraria do Advogado, 2008.

SILVA, Alice Rocha da. Migração, segurança internacional e direitos humanos: os desafios a serem enfrentados e reflexões sobre a contribuição do direito administrativo global. [2016]. Disponível em: http://www.publicacoesacademicas.uniceub.br/jus/article/ viewFile/3936/2998. Acesso em: 28 dez. 2018.

VEDOVATO, Luís Renato. A nova lei de migração e a acolhida humanitária. [2018]. Disponível em: http://www.evento.odh. unicamp.br/simposio2018/wp-content/uploads/2018/09/Luis_Renato Vedovato_177.pdf. Acesso em: 28 dez. 2018.

WALDMAN, Tatiana Chang. Sobre a condição migratória não documentada e suas diversas camadas. In: JUBILUT, Liliana Lyra; FRINHANI, Fernanda de Magalhães Dias; LOPES, Rachel de Oliveira (org.). Migrantes forçados: conceitos e contextos. Boa Vista: Editora da UFRR, 2018. p. 43-67. 
Aylle de Almeida Mendes é mestre em Proteção dos Direitos Fundamentais da Universidade de Itaúna (UIT).

E-mail: ayllemendes@gmail.com

Endereço profissional: Rua Raimundo Penalva, n. 70, Vila Guilhermina, Montes Claros, MG. CEP: 39401-010.

ORCID: http://orcid.org/0000-0002-9331-7503

Deilton Ribeiro Brasil é pós-doutor em Direito pela Università degli Studi di Messina, Itália. Doutor em Direito pela UGF-RJ. Professor da Graduação e do PPGD da Universidade de Itaúna (UIT) e das Faculdades Santo Agostinho (FASASETE/AFYA).

E-mail: deilton.ribeiro@terra.com.br

Endereço profissional: Rua Francisco Vale, n. 336, Boa More, Barbacena, MG. CEP: 36201-030.

ORCID: http://orcid.org/0000-0001-7268-8009 